\title{
DESENVOLVIMENTO DE UMA COLUNA DE FLOTAÇÃO PILOTO DE BAIXO CUSTO E EMPREGO NO BENEFICIAMENTO DE MINERAIS FERROSOS*
}

\author{
Maurício Guimarães Bergerman ${ }^{1}$ \\ Daniela Gomes Horta ${ }^{1}$ \\ Débora da Silva Costa \\ Dimas José Neto ${ }^{2}$ \\ Grasiela Otto ${ }^{2}$ \\ Jeísa Flávia Passos Rodrigues² \\ Karine Dias Gomes ${ }^{3}$ \\ Layssa Silveira Maia ${ }^{3}$ \\ Leandro Postilhone Rosa Magalhães ${ }^{2}$ \\ Rodrigo Cassani ${ }^{3}$
}

\section{Resumo}

O objetivo deste estudo é apresentar a construção de uma coluna de flotação piloto de baixo custo, que será utilizada para concentração de minerais ferrosos. 0 trabalho contém os passos seguidos no projeto de construção do equipamento (descrição dos sistemas operacionais; dimensionamento; desenhos do projeto; levantamento dos materiais, fornecedores e orçamentos; testes dos sistemas de aeração e bombeamento, além da montagem) e também, os resultados dos ensaios exploratórios realizados com uma amostra de minério de ferro, contendo $38 \%$ de $\mathrm{Fe}$, doada pela Companhia Vale S. A. proveniente da Mina de Alegria, Mariana/MG. Nos ensaios preliminares, obtiveram-se teores de Fe no concentrado próximos a $50 \%$ e uma recuperação metalúrgica em torno de $90 \%$. O resultado foi considerado adequado, tendo em vista que foi realizado apenas um estágio de concentração. Dessa forma, conclui-se que a montagem e operação da coluna foram satisfatórias e o protótipo pode ser utilizado como unidade piloto para a avaliação de diferentes condições de processo.

Palavras-chave:Coluna de flotação; Recuperação metalúrgica; Minério de ferro.

\section{DEVELOPMENT OF A PILOT FLOTATION COLUMN OF LOW COST AND EMPLOYMENT IN THE PROCESSING OF FERROUS MINERALS}

\section{Abstract}

The objective of this study is to present the construction of a low-cost pilot flotation column, which will be used in the concentration of ferrous minerals. The work contains the steps of the project and construction of the equipment (description of operating systems; empirical scaling; project drawings; survey of materials, suppliers and budgets; tests of aeration and pumping systems, and assembly) and, the results of the exploratory experiments, conducted with iron ore containing $38 \%$ of $\mathrm{Fe}$, donated by company Vale S.A. from Alegria mine, Mariana/MG. The preliminary experiments indicated concentrates with near $50 \%$ of iron and a metallurgical recovery of approximately $90 \%$. The outcome was considered adequate considering that only one stage of concentration was done. This way, the assembly and the operation of the column were satisfactory and that the prototype can be used as pilot unit for different process conditions evaluation.

Keywords: Column flotation; Metallurgical recovery; Iron ore.

1 Doutor(a) em Engenharia Mineral, professor(a) adjunto, Núcleo de Engenharia de Minas, UNIFAL, Poços de Caldas, MG, Brasil.

2 Graduando(a) em Engenharia de Minas, UNIFAL, Poços de Caldas, MG, Brasil.

3 Graduando(a) em Engenharia Química, UNIFAL, Poços de Caldas, MG, Brasil.

\footnotetext{
* Contribuição técnica ao $44^{\circ}$ Seminário de Redução de Minério de Ferro e Matérias-primas, 15ํ Simpósio Brasileiro de Minério de Ferro e $2^{\circ}$ Simpósio Brasileiro de Aglomeração de Minério de Ferro, 15 a 18 de setembro de 2014, Belo Horizonte, MG, Brasil.
} 


\section{INTRODUÇÃO}

A coluna de flotação é um equipamento dinâmico que confere trajetórias distintas às partículas com diferentes graus de hidrofobicidade. Apresenta seção circular ou retangular, com a altura mais desenvolvida do que o diâmetro.

O material que alimenta a coluna (polpa) é previamente condicionado com reagentes específicos em tanques agitados e introduzido na coluna a aproximadamente dois terços de sua altura total. No interior da coluna, a polpa realiza uma trajetória descendente em contracorrente com um fluxo ascendente de ar, introduzido no sistema pela parte inferior.

$\mathrm{O}$ ar introduzido tem a finalidade de gerar bolhas ascendentes e coletar as partículas hidrofóbicas, transportando-as para a espuma. Esta técnica utiliza o princípio de contracorrente para colocar em contato o fluxo de polpa com o fluxo de ar. A colisão entre partícula hidrofóbica e bolha de ar faz com que ocorra adesão entre essas espécies, formando uma bolha com a superfície mineralizada, que exibe uma densidade aparente menor do que a do meio e, portanto, flutua até o topo da coluna. As partículas hidrofílicas que não se aderem às bolhas são retiradas na base do equipamento, caracterizando o afundado. Já as partículas carreadas pelas bolhas formam uma camada de espuma mineralizada, sendo retiradas por transbordo, caracterizando o material flutuado [1].

Conforme Oliveira e Aquino [2], a coluna pode ser dividida em duas regiões distintas: i- Zona de coleta: é a seção que compreende desde o aerador até a interface polpa/espuma, onde ocorre os fenômenos de colisão e adesão de partículas hidrofóbicas na bolha ascendente, formando o agregado (partícula/bolha) que é transportado até a camada de espuma.

ii- Zona de limpeza: compreende a seção que vai desde a interface polpa/espuma até o transbordo, onde há a adição de água de lavagem eliminando as partículas hidrofílicas arrastadas.

A flotação em coluna apresenta certas vantagens sobre a flotação em células mecânicas [3]: Redução do arraste de partículas hidrofílicas para a zona de limpeza, o que gera aumento de seletividade e possibilita menor número de estágios de limpeza, simplificando o circuito; Maior tempo de residência das bolhas na polpa em virtude da altura desenvolvida da zona de coleta, proporcionando maiores taxas de colisão e adesão; Ausência de agitação na região da coleta, aumentando a probabilidade da partícula não desprender-se da bolha; Redução do consumo energético por tonelada de minério processada; Redução da área construída da usina de beneficiamento, devido à forma compacta do equipamento.

As principais variáveis do processo de flotação em coluna podem ser classificadas em manipuladas e controladas. Entre as variáveis manipuladas estão: vazão de água de lavagem, vazão do afundado e vazão de alimentação de ar, que são ajustáveis diretamente pela atuação em válvulas e bombas. Dentre as variáveis controladas tem-se: recuperação, percentagem de sólidos no concentrado, teor do metal de interesse, bias (fluxo residual de água através da zona de limpeza), altura da camada de espuma e hold up do ar (fração volumétrica ocupada pelo ar), sendo as três primeiras também chamadas de variáveis de controle primárias e as três ultimas de variáveis de controle secundárias [1]. Estas variáveis controladas não são ajustáveis diretamente e dependem de valores ótimos das variáveis manipuladas. Assim, as variáveis manipuladas determinam as controladas secundárias que então, estabilizam a coluna em taxas ótimas de recuperação e teor.

\footnotetext{
* Contribuição técnica ao $44^{\circ}$ Seminário de Redução de Minério de Ferro e Matérias-primas, 15ํ Simpósio Brasileiro de Minério de Ferro e $2^{\circ}$ Simpósio Brasileiro de Aglomeração de Minério de Ferro, 15 a 18 de setembro de 2014, Belo Horizonte, MG, Brasil.
} 
A vazão de ar deve proporcionar tamanho de bolha adequado e uma distribuição homogênea das bolhas ao longo da seção de recuperação da coluna [4]. A remoção do afundado deve ser feita de maneira a garantir a estabilidade da interface polpa/espuma frente às oscilações da vazão de água de lavagem e principalmente da alimentação. Já a vazão da água de lavagem deve reduzir o arraste de sólidos hidrofílicos, facilitar o escoamento da espuma para calha e fornecer uma velocidade superficial do bias adequada, de forma a impedir com que a água presente na polpa da zona de coleta se reporte a espuma [4].

As variáveis de controle primárias são ajustadas indiretamente pela estabilidade da coluna em valores pré-estabelecidos de altura da camada de espuma, do bias e do hold up, que por sua vez, são controlados respectivamente pelas vazões do afundado, da água de lavagem e da entrada de ar [5].

A interface polpa/espuma determina o limite entre a zona de coleta e de limpeza. $O$ nível de polpa determina a altura da zona de coleta, enquanto que a altura da camada de espuma determina a zona de limpeza. Se a interface é muito baixa, a zona de coleta fica reduzida e arecuperação pode diminuir, caso contrário, a zona de limpeza fica menor, o que significa diminuir a drenagem da espuma, deteriorando a seletividade [1].

O bias promove o retorno para a região de coleta das partículas hidrofílicas que foram arrastadas, implicando na melhoria da seletividade do processo. Normalmente é estimado pela diferença entre a vazão do afundado e a vazão da polpa de alimentação [1]. O aumento excessivo deste parâmetro promove turbulência e induz movimentos axiais na zona de limpeza [6].

A relação entre o hold up do ar na zona de coleta e a vazão de ar é usada para definir o regime de flotação. Aumentando-se a vazão de ar até certo ponto, o hold up aumenta linearmente, o que caracteriza uma distribuição homogênea de bolhas. Após esse ponto, o hold up se torna instável com o aparecimento de bolhas grandes perdendo o regime de fluxo pistonado [7].

A princípio, este trabalho se direcionou ao estudo dos sistemas operacionais da coluna de flotação. Posteriormente, os objetivos se concentraram em torno do dimensionamento; proposição de alternativas para a confecção dos sistemas de aeração, água de lavagem, alimentação e descarga, além da efetiva construção do protótipo e verificação de seu desempenho na concentração de minerais.

Este estudo é parte do projeto multidisciplinar que os autores desenvolveram para a formação no Bacharelado Interdisciplinar em Ciência e Tecnologia, primeiro ciclo dos cursos de engenharia da Universidade Federal de Alfenas (Unifal-MG). A motivação para concepção deste trabalho surgiu devido ao fato de a universidade não dispor de um equipamento de flotação colunar para o ensino e pesquisa e que os equipamentos disponíveis para aquisição no mercado são de custo relativamente alto.

\section{MATERIAIS E MÉTODOS}

As atividades desenvolvidas no trabalho consistiram na descrição dos sistemas operacionais da coluna visando propostas alternativas para construção do protótipo; dimensionamento da coluna com base em parâmetros operacionais encontrados na literatura; confecção dos croquis para facilitar a compra e fabrico das peças; inventário dos materiais a serem utilizados; pesquisa dos preços dos materiais necessários no mercado; compra dos materiais utilizados; teste de funcionamento

\footnotetext{
* Contribuição técnica ao $44^{\circ}$ Seminário de Redução de Minério de Ferro e Matérias-primas, 15ํ Simpósio Brasileiro de Minério de Ferro e $2^{\circ}$ Simpósio Brasileiro de Aglomeração de Minério de Ferro, 15 a 18 de setembro de 2014, Belo Horizonte, MG, Brasil.
} 
do aerador; testes do sistema de bombeamento; montagem do equipamento e ensaios para verificar o desempenho do mesmo.

\subsection{Descrição dos Sistemas Operacionais da Coluna Visando à Construção}

\subsubsection{Aeração e sistema de geração de bolhas}

Os sistemas de geração de bolhas são dispositivos perfurados por onde o ar comprimido é injetado na coluna. Podem ser internos (o ar é introduzido diretamente na polpa através de um difusor poroso no interior da coluna) ou externos (o ar entra em contato previamente com a água ou com a polpa antes de ser insuflado no sistema) [6]. De acordo com Aquino, Oliveira e Fernandes [4], um gerador de bolhas eficaz é aquele capaz de gerar bolhas de 0,5 a 2,0 $\mathrm{mm}$ de diâmetro, com velocidade superficial de ar entre 1,0 e $3,0 \mathrm{~cm} / \mathrm{s}$ e hold up de 15 a $20 \%$.

Atualmente, empregam-se os mecanismos cavitation sparger, que geram bolhas por cavitação e apresentam a configuração interna de um tubo de Venturi.

O sistema de aeração adotado no projeto é do tipo interno, constituído de uma vela de filtro domiciliar conectada a um compressor e instada abaixo da zona de coleta. As bolhas são geradas pelo alívio de pressão após a passagem do ar pelos poros da vela.

\subsubsection{Sistema de aspersão de água de lavagem}

A água de lavagem é injeta de forma suave na zona de limpeza através de aspersores, que podem ser internos ou externos à espuma [6]. Os aspersores externos são instalados acima da camada de espuma estando livres de entupimentos e permitem fácil inspeção visual [2]. Já o distribuidor interno é colocado no interior da camada de espuma, a uma profundidade entre 10 a $20 \mathrm{~cm}$ a baixo do nível do transbordo, produz um flutuado com maior percentagem de sólidos, comparado ao dispositivo anterior, mas a inspeção é mais difícil e ocorrem frequentes entupimentos [2].

O sistema de aspersão utilizado é externo à espuma, constituído por uma hidropistola com jato regulável (Tramontina®) acoplada a uma mangueira de abastecimento de água e instalada na porção superior do equipamento.

\subsubsection{Dosagem de reagentes e sistema condicionamento}

Os reagentes são adicionados de acordo com as dosagens estabelecidas para o ensaio em tanques dotados de agitação mecânica (condicionadores), onde permanecem durante certo tempo em contato com a polpa, para melhor adsorver na superfície mineral [8].

Para o condicionamento e dispersão da polpa durante a operação da coluna, empregou-se um tanque agitado, onde os reagentes foram dosados com o auxílio de proveta graduada e pipeta a partir de uma solução previamente preparada.

\subsubsection{Sistema de alimentação}

A polpa previamente condicionada e a uma dada percentagem de sólidos alimenta continuamente a coluna a aproximadamente $1 / 3$ de sua altura partir do topo.

A alimentação da coluna protótipo é contínua controlada por uma bomba peristáltica (Provitec®, modelo AWG 5000 - ABS) e introduzida no centro do equipamento por um tubo metálico com a saída dobrada.

\footnotetext{
* Contribuição técnica ao 44ํ Seminário de Redução de Minério de Ferro e Matérias-primas, 15 Simpósio Brasileiro de Minério de Ferro e 2ํ Simpósio Brasileiro de Aglomeração de Minério de Ferro, 15 a 18 de setembro de 2014, Belo Horizonte, MG, Brasil.
} 


\subsubsection{Descarga do flutuado e afundado}

O flutuado deixa a coluna por transbordo, sendo coletado por uma calha na porção superior. Já o afundado é coletado na base da coluna por uma bomba peristáltica (Provitec®, modelo AWG 5000 - ABS). A vazão de descarga do afundado é utilizada para controlar a altura da espuma na zona de limpeza, então, tal parâmetro deve ser monitorado para garantir a existência desta espuma [6].

No projeto, o afundado é removido por meio de uma peça em formato de funil, que se encontra conectado à câmara do aerador e, que direciona o fluxo para uma mangueira canalizando-o até a bomba peristáltica que controla as vazões deste produto.

$\mathrm{Na}$ calha de coleta do flutuado, há uma mangueira responsável por introduzir a água que quebra a espuma e arrasta as partículas coletadas.

\subsection{Dimensionamento Empírico}

Com base na vazão volumétrica de polpa na alimentação $(Q a)$, pode-se determinar aproximadamente o volume total do reator somando-se esta vazão volumétrica de polpa com a vazão volumétrica de ar $(Q g)$ e multiplicando-se pelo tempo médio de residência $\left(t_{\text {res }}\right)$, conforme a Equação 1 adaptada de Viana [9].

$$
V_{\text {total }}=\left(Q_{a}+Q_{g}\right) \cdot t_{\text {res }}
$$

Para efetuar os cálculos, utilizaram-se alguns parâmetros operacionais (Tabela 1) transportados dos ensaios de flotação em coluna piloto realizados nos estudos de Nunes, Couto e França [10].

Tabela 1. Dados operacionais adotados

\begin{tabular}{cc}
\hline CONDIÇÕES DE OPERAÇÃO & VALOR \\
\hline Vazão volumétrica de polpa (ml/min) & 633 \\
\hline Hold up do ar (\%) & 20 \\
\hline Tempo médio de residência (min) & 15 \\
\hline Velocidade superficial água de lavagem (cm/s) & 0,10 \\
\hline Vazão volumétrica água de lavagem (ml/min) & 245 \\
\hline Fonte: Valores adaptado de Nunes Couto e França [10].
\end{tabular}

Como é sabido que a razão da vazão de água de lavagem pela área da seção da coluna resulta na velocidade superficial de água de lavagem e que a coluna é um cilindro regular, suas dimensões foram determinadas em $7,2 \mathrm{~cm}$ de diâmetro interno e $280 \mathrm{~cm}$ de altura total. A coluna foi construída em acrílico.

\subsection{Croquis do Projeto}

Com base nas dimensões calculadas e em informações coletadas durante uma visita a planta piloto do Setor de Tecnologia Mineral do Centro de desenvolvimento da Tecnologia Nuclear (CDTN), construiu-se os desenhos em CAD das peças de acrílico do projeto. Na Figura 1 são apresentadas as vistas frontais de cada peça.

\footnotetext{
* Contribuição técnica ao $44^{\circ}$ Seminário de Redução de Minério de Ferro e Matérias-primas, 15ํ Simpósio Brasileiro de Minério de Ferro e $2^{\circ}$ Simpósio Brasileiro de Aglomeração de Minério de Ferro, 15 a 18 de setembro de 2014, Belo Horizonte, MG, Brasil.
} 

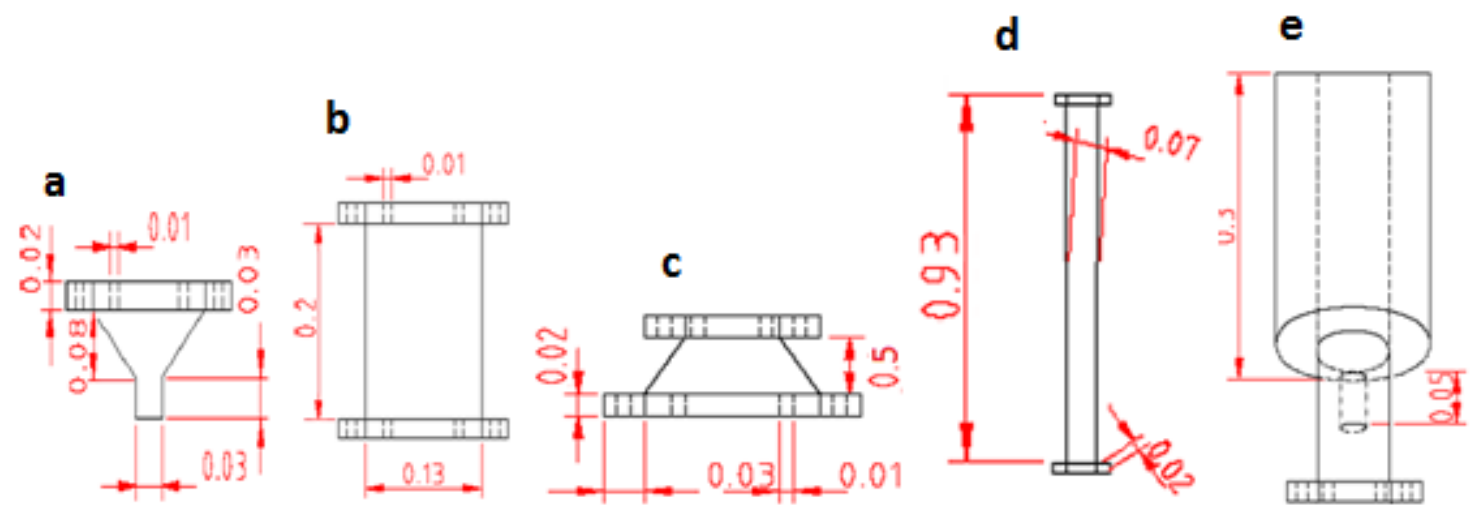

Figura 1. (a) funil de descarga do afundado; (b) câmara do aerador; (c) redutor de diâmetro; (d) módulo do corpo da coluna; (e) módulo superior com calha. Fonte: Autoria própria.

\subsection{Inventário dos Materiais, Orçamentos e Recursos Financeiros}

Os materiais utilizados para a execução e montagem do protótipo (Tabela 2) foram subdivididos em: materiais para Água de lavagem, Aeração, Alimentação, Descarga de produtos, Condicionamento e Peças de acrílico.

Tabela 2.Lista de materiais adquiridos

\begin{tabular}{|c|c|}
\hline SISTEMA & MATERIAIS \\
\hline Peças de acrílico & $\begin{array}{c}\text { Dois módulos flangeados nas duas extremidades }(\varnothing=7 \\
\mathrm{cm} \times \mathrm{h}=93,3 \mathrm{~cm}) \text {; módulo superior com calha } \\
\text { circundante; câmara do aerador com flanges nas duas } \\
\text { extremidades }(\varnothing=13 \mathrm{~cm} \times \mathrm{h}=20 \mathrm{~cm}) \text {; redutor de } \\
\text { diâmetro da câmara do aerador para o corpo da coluna } \\
\left(\emptyset_{\text {maior }}=13 \mathrm{~cm}, \emptyset_{\text {menor }}=7 \mathrm{~cm}\right) ; \text { funil com base } \\
\text { flangeada. }\end{array}$ \\
\hline Água de lavagem & Hidropistola (Tramontina ${ }^{\circledR}$ ) \\
\hline Aeração & $\begin{array}{c}\text { Compressor de ar (pressão mín. } 3 \text { bar) e vela de filtro } \\
\text { doméstica. }\end{array}$ \\
\hline Aliment & $\begin{array}{c}\text { Conexão de mangueira, cano metálico e bomba } \\
\text { peristáltica (vazão mínima } 40 \mathrm{l} / \mathrm{h} \text { ). }\end{array}$ \\
\hline Descarga de produtos & Bomba peristáltica (vazão mínima 50 l/h). \\
\hline Condicionamento & Tanque com agitador mecânico. \\
\hline
\end{tabular}

As mangueiras, conexões e colas foram compradas de acordo com a necessidade, durante a montagem, pois são materiais de baixo custo.

O projeto foi financiado com recursos da Fundação de Apoio da Unifal-MG, obtidos por meio de projetos em parcerias com empresas privadas do setor mineral, totalizando um dispêndio de $R \$ 5.300,00$, sendo que os principais gastos foram de $\mathrm{R} \$ 1.300,00$ com os módulos de acrílico e de $R \$ 3.000,00$ com as duas bombas peristálticas.

Para efeito de comparação, solicitou-se junto a três empresas especializadas na fabricação de equipamentos e peças para laboratórios de mineração, o orçamento de colunas piloto. Os valores das propostas variaram de $R \$ 20.000,00$ a $R \$$ $36.000,00$ por uma coluna similar a construída no presente trabalho, sem incluir as bombas de alimentação e descarga.

* Contribuição técnica ao 44ํㅗㄴ Seminário de Redução de Minério de Ferro e Matérias-primas, 15ㅇ Simpósio Brasileiro de Minério de Ferro e 2o Simpósio Brasileiro de Aglomeração de Minério de Ferro, 15 a 18 de setembro de 2014, Belo Horizonte, MG, Brasil. 


\subsection{Teste do Aerador}

Para verificar se o sistema de aeração com vela de filtro seria adequado, atrelou-se uma vela de filtro em um compressor de ar por meio de uma mangueira. A vela foi mergulhada em um béquer, contendo água com corante para facilitar a visualização das bolhas. A vazão de ar foi controlada manualmente, sem controle quantitativo.

\subsection{Teste das Bombas}

Preparou-se aproximadamente 6 litros de polpa de minério de ferro, sob agitação mecânica a $5 \%$ de sólidos. Em seguida mergulhou-se a mangueira de sucção da bamba nesta polpa e elevou-se a mangueira de recalque a uma altura de 2,5 $\mathrm{m}$ da bomba (simulando o recalque da bomba de alimentação da coluna). Então, procedeu-se a medida da vazão, com o auxílio de uma proveta e um cronômetro, para 100 e 50 ciclos da bomba. O mesmo procedimento foi realizado para outras polpas com $10 \%, 20 \%$ e $50 \%$ de sólidos para a mesma bomba. O mesmo procedimento foi adotado para a segunda bomba.

\subsection{Montagem}

A montagem do protótipo seguiu os passos descritos no fluxograma da Figura 2. Na Figura 3 pode ser visto os detalhes da montagem dos sistemas da coluna.

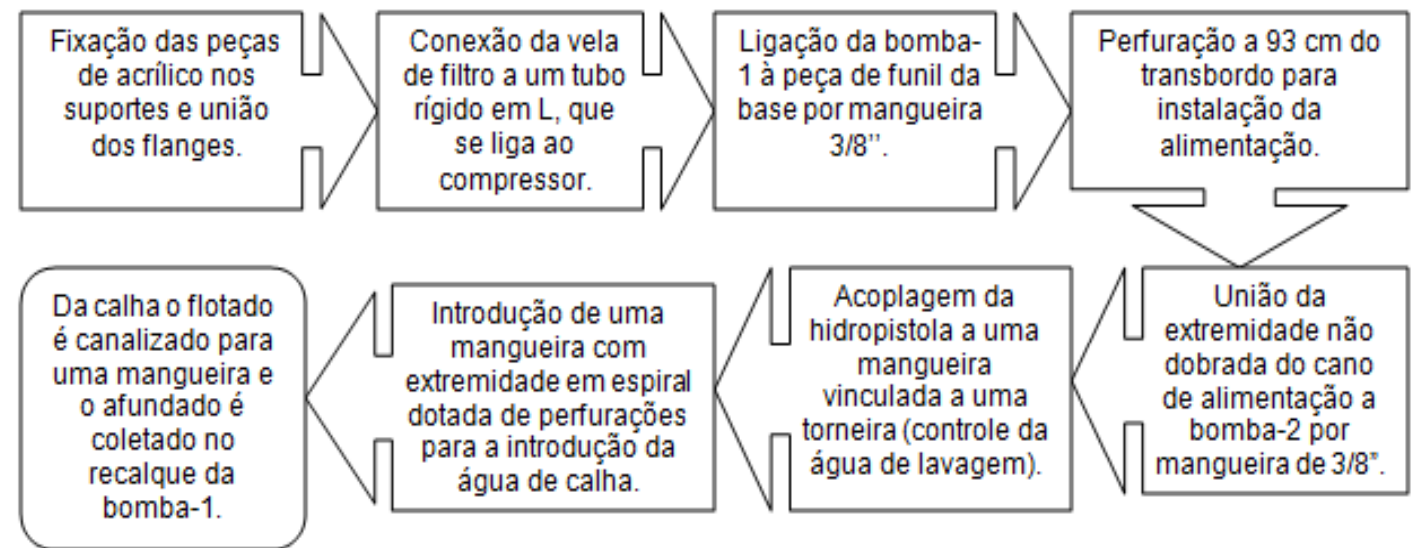

Figura 2. Descrição das etapas de montagem da coluna. Fonte: Autoria própria.

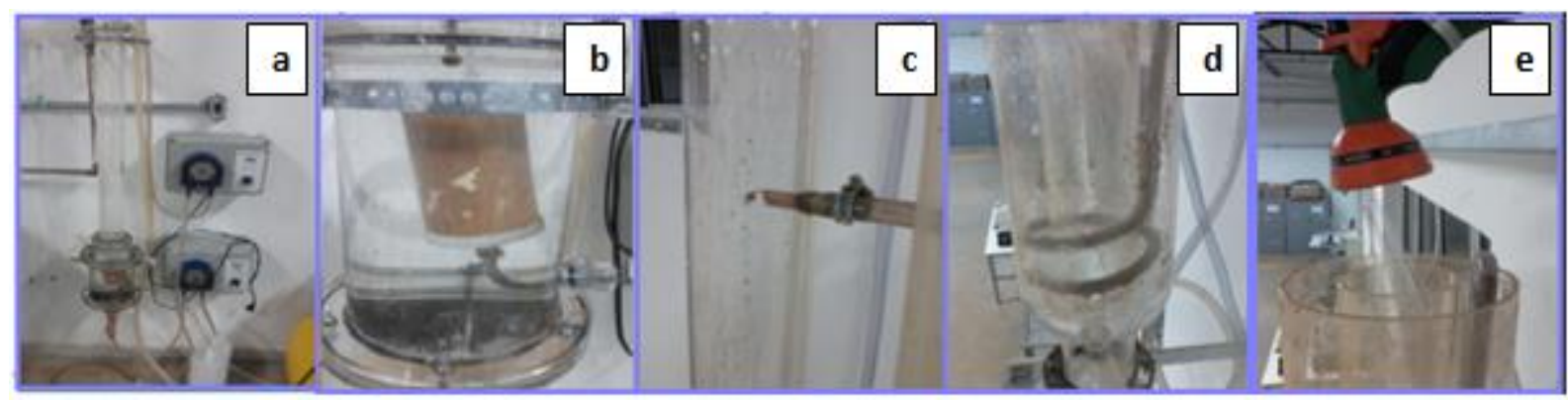

Figura 3.Em (a): Bomba superior de alimentação e a inferior de descarga do afundado. (b): Aerador confeccionado com vela de filtro. (c): Entrada de alimentação. (d): Sistema de água de calha. (e): aspersor externo de água de lavagem. Fonte: Autoria própria.

* Contribuição técnica ao 44 Seminário de Redução de Minério de Ferro e Matérias-primas, 15ํ Simpósio Brasileiro de Minério de Ferro e $2^{\circ}$ Simpósio Brasileiro de Aglomeração de Minério de Ferro, 15 a 18 de setembro de 2014, Belo Horizonte, MG, Brasil. 


\subsection{Ensaios Exploratórios}

\subsubsection{Materiais e Preparação da Amostra}

Os $200 \mathrm{~kg}$ da amostra inicial foram separados em alíquotas de $10 \mathrm{~kg}$. Para cada ensaio foram utilizadas duas destas alíquotas, montada a pilha longitudinal de homogeneização e retirado $12,6 \mathrm{~kg}$ para a realização do ensaio de flotação. Não se efetuou moagem e classificação do material, pois este já apresentava granulometria abaixo de $105 \mu \mathrm{m}$, tendo em vista que foi coletado na etapa de alimentação da flotação da usina de Alegria.

\subsubsection{Análise granulométrica da alimentação e densidade das partículas}

A análise granulométrica da alimentação foi realizada por peneiramento a úmido nas malhas: 212, 150, 106, 75, 53 e $45 \mu \mathrm{m}$.

A densidade das partículas foi determinada por picnometria, de acordo com método descrito por Sampaio e Silva [11], utilizando-se picnômetro de $50 \mathrm{ml}$.

\subsubsection{Determinação do teor de Fe e eficiência do processo}

De posse da massa específica, emprega-se as equações 2 e 3, para o cálculo do teor de $\mathrm{Fe}$ das amostras. Isto considerando que existe apenas hematita $\left(\mathrm{Fe}_{2} \mathrm{O}_{3}\right)$ e sílica $\left(\mathrm{SiO}_{2}\right)$ e que os demais constituintes representam menos de $5 \%$ da amostra [10].

$$
\begin{aligned}
\rho_{p} & =\frac{1}{\frac{f_{h}}{\rho_{h}}+\frac{\left(1-f_{h}\right)}{\rho_{s}}} \\
\% F e & =0,7 \cdot f_{h} \cdot 100
\end{aligned}
$$

Em que $\rho_{p}$ é a massa específica média das amostras; $\rho_{h}$ é a massa específica da hematita $\left(5,2 \mathrm{~g} / \mathrm{cm}^{3}\right) ; \rho_{s}$ é a massa específica do quartzo $\left(2,65 \mathrm{~g} / \mathrm{cm}^{3}\right)$ e $f_{h}$ éa fração de hematita na amostra. Da equação 2 obtém-se a fração de hematita e da equação 3 obtém-se o teor de ferro.

Para efeito de comparação, realizou-se também uma análise química pelo método de fluorescência de Raios-x no laboratório da Mineração Curimbaba LTDA.

A eficiência do processo de flotação é medida em função do teor do material útil obtido no concentrado e, também em relação à recuperação metalúrgica desse material no concentrado [10].

Em termos de teor de $\mathrm{Fe}$, a recuperação metálica é dada pela equação 4 e relaciona o conteúdo de ferro no concentrado ao teor de ferro da alimentação [10].

$$
\operatorname{RMet}(\%)=\left(\frac{\% F e_{\text {alim }}-\% F e_{r e j}}{\% F e_{\text {conc }}-\% F e_{\text {rej }}}\right) *\left(\frac{\% F e_{\text {con }}}{\% F e_{\text {alim }}}\right) \text { ou }\left(\frac{\% F e_{\text {con }} \cdot m_{\text {con }}}{\% F e_{\text {alim }} \cdot m_{\text {alim }}}\right) \cdot 100
$$

Em que $\% F e_{c o n}, \% F e_{a l i m}$ e $\% F e_{r e j}$ são os teores de ferro no concentrado, na alimentação e no rejeito, $m_{\text {con }}$ e $m_{\text {alim }}$ são as massas amostradas do concentrado e da alimentação respectivamente.

\footnotetext{
* Contribuição técnica ao $44^{\circ}$ Seminário de Redução de Minério de Ferro e Matérias-primas, 15ํ Simpósio Brasileiro de Minério de Ferro e $2^{\circ}$ Simpósio Brasileiro de Aglomeração de Minério de Ferro, 15 a 18 de setembro de 2014, Belo Horizonte, MG, Brasil.
} 


\subsubsection{Procedimento do ensaio na coluna}

Os reagentes utilizados na flotação de minério de ferro da mina de Alegria foram: amina (EDA-C) da Clariant ${ }^{\circledR}$ como coletor de silicatos, na dosagem de $250 \mathrm{~g} / \mathrm{t}$ de $\mathrm{SiO}_{2}$; amido de milho (Maisena) gelatinizado com $\mathrm{NaOH}$ como depressor de hematita na dosagem de $1.000 \mathrm{~g} / \mathrm{t}$ e solução de $\mathrm{NaOH}$ a $10 \%$ como regulador de $\mathrm{pH}$. As dosagens foram as mesmas utilizadas industrialmente na mina de Alegria para minério com o mesmo teor de sílica da amostra ensaiada.

Os ensaios de flotação em coluna foram realizados conforme os passos descritos na Figura 4.

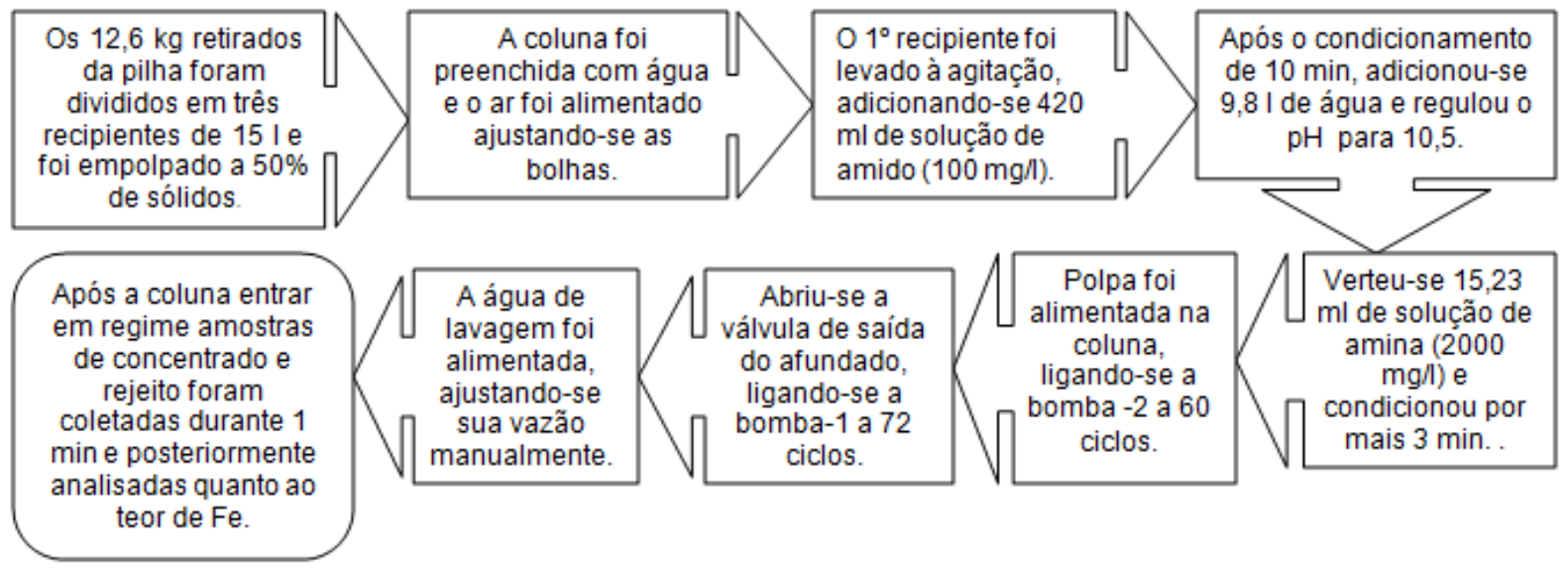

Figura 4. Procedimento do ensaio em coluna. Fonte: Autoria própria.

No momento em que o primeiro recipiente estava com a polpa pela metade, 0 conteúdo do segundo recipiente era levado à agitação em outro agitador e o processo se repetia (condicionamento com amido, expansão da polpa, medida de $\mathrm{pH}$ e condicionamento com amina). Então quando o conteúdo do primeiro recipiente estava se esgotando, vertia-Ihe o conteúdo do segundo, de modo que o fluxo de alimentação permanecesse constante.

\section{RESULTADOS E DISCUSSÃO}

\subsection{Teste do Aerador}

No teste de aeração, observou-se que a uma vazão baixa de ar a aeração não foi suficiente, uma vez que se gerava um número reduzido de bolhas. Por outro lado, regulando-se a válvula de saída de ar para uma vazão um pouco mais elevada, notou-se que a geração de bolhas se dava em toda a área superficial da vela de filtro e que a quantidade de bolhas aumentou. Observou-se ainda, que a distribuição de bolhas permaneceu mais ou menos uniforme, apesar da presença de algumas bolhas grandes.

Alterando-se a vazão de ar para taxas mais elevadas, verificou-se um aumento substancial no tamanho e na quantidade de bolhas em comparação com as situações anteriores e percebeu-se um deslocamento turbulento de água durante a passagem das bolhas.

A vela de filtro constitui uma alternativa para se construir um difusor de ar, uma vez que as bolhas geradas não foram muito grandes e que tendo um controle da vazão de ar, pode-se obter um fluxo adequado com tamanhos de bolhas uniformes.

* Contribuição técnica ao 44 Seminário de Redução de Minério de Ferro e Matérias-primas, 15ㅇ Simpósio Brasileiro de Minério de Ferro e 2o Simpósio Brasileiro de Aglomeração de Minério de Ferro, 15 a 18 de setembro de 2014, Belo Horizonte, MG, Brasil. 


\subsection{Teste das Bombas}

Para a polpa com $50 \%$ de sólidos, as partículas sedimentaram no interior da mangueira, obstruindo a entrada da bomba. Portanto, polpas acima desta quantidade de sólidos foram excluídas do trabalho.

Os resultados dos testes para as outras concentrações de sólidos encontram-se na Figura 5.

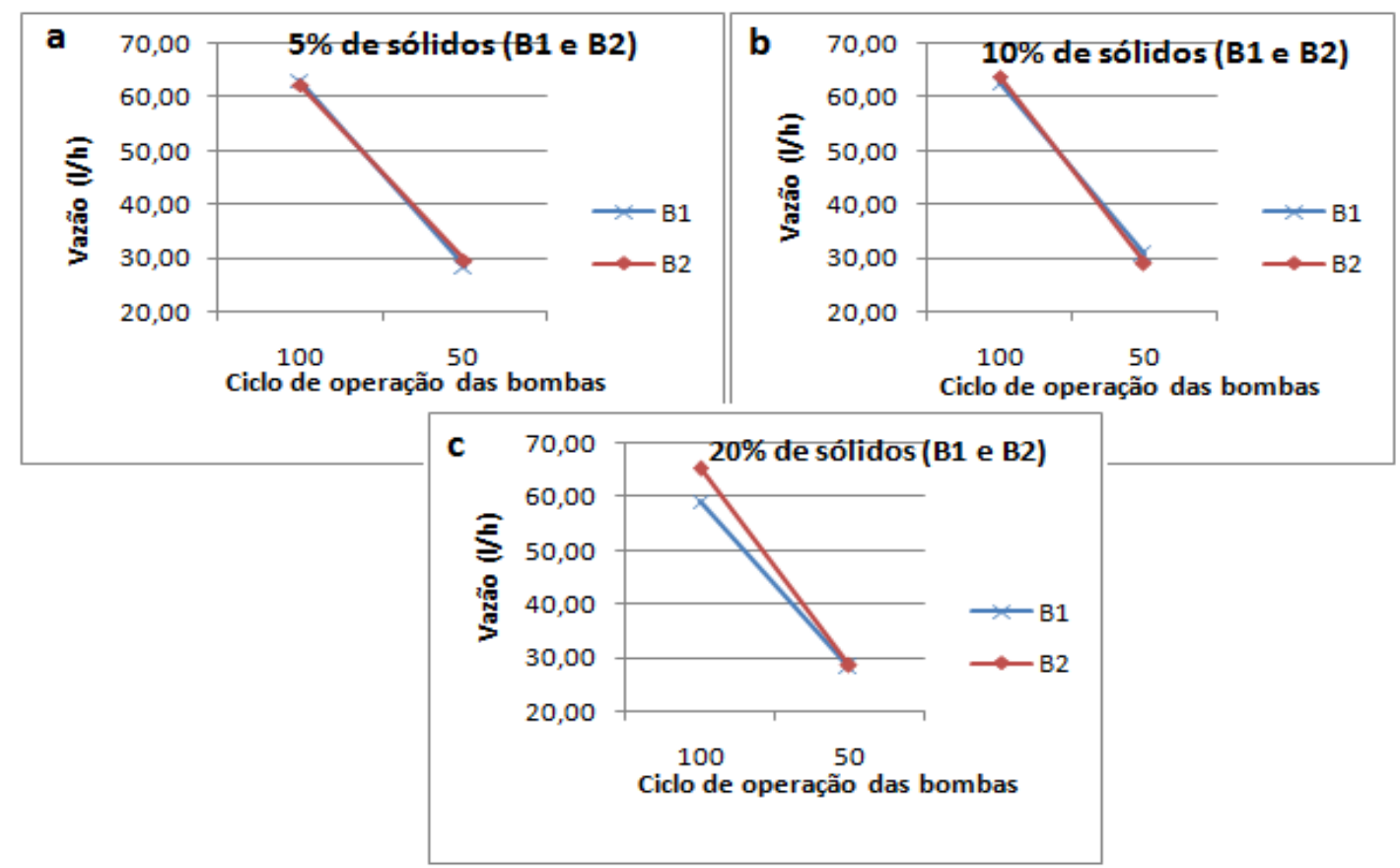

Figura 5.Gráficos de vazão de polpa por ciclos das bombas.

Para uma mesma velocidade de rotação em ambas as bombas, independentemente da porcentagem de sólidos, não houve variação significativa de vazão. Este resultado corrobora com a característica das bombas peristálticas de que a natureza do fluido não interfere na vazão.

A porcentagem de sólidos adotada para operar a coluna foi de $30 \%$. Valor este estimado entre os $50 \%$ de sólidos que causam entupimento e o máximo testado com sucesso (20\% de sólidos).

\subsection{Ensaios Exploratórios de Flotação}

\subsubsection{Análise granulométrica da alimentação.}

A Figura 6 representa a distribuição de tamanhos das partículas da amostra alimentada na coluna.

\footnotetext{
* Contribuição técnica ao 44 Seminário de Redução de Minério de Ferro e Matérias-primas, 15ํ Simpósio Brasileiro de Minério de Ferro e $2^{\circ}$ Simpósio Brasileiro de Aglomeração de Minério de Ferro, 15 a 18 de setembro de 2014, Belo Horizonte, MG, Brasil.
} 


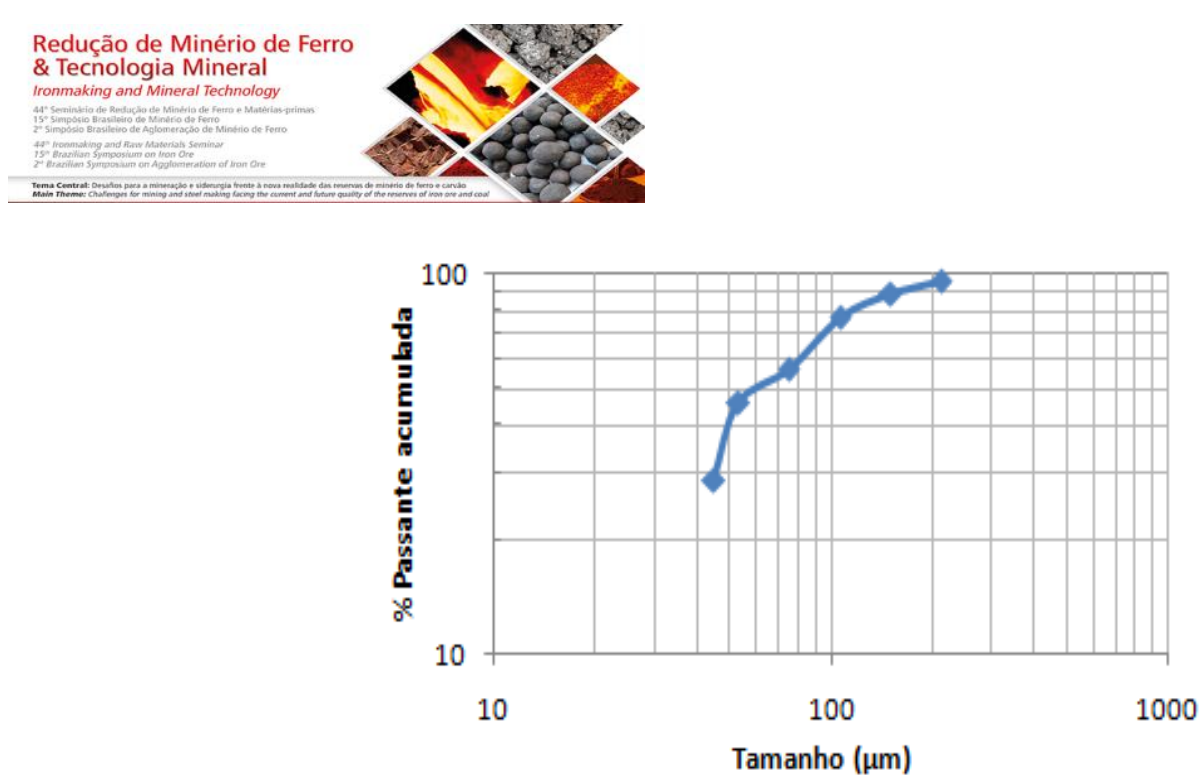

Figura 6. Análise granulométrica da amostra de alimentação.

Verificou-se que aproximadamente $29 \%$ das partículas encontram-se abaixo de 45 $\mu \mathrm{m}$ e que aproximadamente $90 \%$ estão abaixo de $150 \mu \mathrm{m}$, o que caracteriza uma amostra com estreita faixa de tamanhos. Segundo Nunes, Couto e França [10], o ideal para a flotação seria um $\mathrm{P}_{90}$ abaixo de $105 \mu \mathrm{m}$.

\subsubsection{Densidade relativa e teor da amostra}

A densidade relativa da amostra de minério de ferro utilizada na flotação em coluna foi $3,61 \mathrm{~g} / \mathrm{cm}^{3}$, correspondendo ao teor de ferro de $38 \%$, próximo ao valor obtido por meio de análise química realizada no laboratório da Mineração Curimbaba, na qual se obteve um teor de $36 \%$ de Ferro.

\subsubsection{Testes da flotação em coluna}

Foram conduzidos dois ensaios na coluna, para o primeiro ensaio realizou-se duas amostragens e no segundo apenas uma, em decorrência da coluna ter perdido o regime de operação. Os resultados são mostrados na Tabela 3, em que $\mathbf{m}$ é a vazão

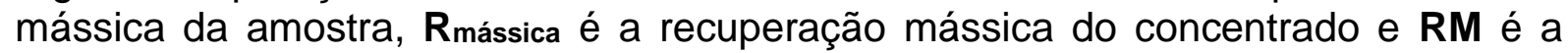
recuperação metalúrgica do ferro no concentrado.

Tabela 3.Resultados de teor e recuperação metalúrgica de Fe nos concentrados

\begin{tabular}{|c|c|c|c|c|c|c|c|c|c|c|}
\hline \multirow{2}{*}{ Ensaio } & \multirow{2}{*}{ Amostra } & \multirow{2}{*}{$\begin{array}{l}\text { Tempo } \\
\text { (mim) }\end{array}$} & \multicolumn{2}{|c|}{ Alimentação } & \multicolumn{2}{|c|}{ Rejeito } & \multicolumn{2}{|c|}{ Concentrado } & \multirow{2}{*}{$\begin{array}{c}R \text { mássica } \\
(\%)\end{array}$} & \multirow{2}{*}{$\begin{array}{l}R M \\
(\%)\end{array}$} \\
\hline & & & $m(\mathrm{~kg} / \mathrm{h})$ & $\% \mathrm{Fe}$ & $m(\mathrm{~kg} / \mathrm{h})$ & $\% \mathrm{Fe}$ & $m(\mathrm{~kg} / \mathrm{h})$ & $\% F e$ & & \\
\hline 1 & 1 & 1 & 8,04 & 38 & 1,97 & 9,08 & 6,07 & 48,65 & 75,50 & 94 \\
\hline & 2 & 10 & 8,86 & 38 & 3,32 & 6,18 & 5,54 & 54,77 & 62,53 & 94 \\
\hline 2 & 1 & 1 & 9,89 & 38 & 2,48 & 2,12 & 7,41 & 48,41 & 74,92 & 99 \\
\hline
\end{tabular}

Partindo-se de uma alimentação com 38\% de ferro metálico, os teores obtidos nos concentrados aumentaram em $28 \%, 44 \%$ e $27 \%$ respectivamente para as amostras 1 e 2 do primeiro ensaio e para a amostra do segundo ensaio. O resultado de enriquecimento mais satisfatório corresponde à segunda amostra do primeiro ensaio, provavelmente pelo fato de ter sido colhida mais tardiamente, quando a operação da coluna já estava em regime e não houve variações operacionais relevantes. Em se tratando de apenas uma etapa de flotação rougher os resultados são promissores, dado a proximidade com as especificações requeridas no mercado: concentrado com no mínimo $65 \%$ de Fe para a redução no alto-forno [12].

\footnotetext{
* Contribuição técnica ao 44 Seminário de Redução de Minério de Ferro e Matérias-primas, 15ㅇ Simpósio Brasileiro de Minério de Ferro e 2o Simpósio Brasileiro de Aglomeração de Minério de Ferro, 15 a 18 de setembro de 2014, Belo Horizonte, MG, Brasil.
} 


\section{CONCLUSÃO}

Com o trabalho foi possível dimensionar e montar uma coluna de flotação de baixo custo ( $\mathrm{R} \$ 5.300,00)$ em comparação ao custo de uma coluna comercial $(R \$ 36.000,00)$. A coluna foi posteriormente testada com relação à aeração e ao processo de flotação propriamente dito.

A utilização de uma vela de filtro como aerador foi suficiente para gerar aeração adequada aos ensaios de flotação.

A concentração de minério de ferro utilizando-se a coluna construída, resultou em concentrados com teores de ferro próximos de $50 \%$, rejeitos com baixos teores desse elemento $(<10 \%)$ e recuperações metalúrgicas acima de $90 \%$ em apenas uma etapa rougher. Assim, o protótipo construído cumpriu com o objetivo no enriquecimento de partículas de minerais ferrosos.

Deve-se destacar que em termos operacionais a coluna funcionou satisfatoriamente, pois não houve nenhum entupimento ou qualquer problema que comprometesse a operação e estabilidade da mesma.

Devido a suas dimensões e ao seu bom funcionamento, a unidade construída tem plenas condições de ser utilizada como unidade piloto para a avaliação de diferentes condições de processo.

\section{Agradecimentos}

A Vale S/A, pelo fornecimento da amostra de minério, ao Setor de Tecnologia Mineral do Centro de Desenvolvimento da Tecnologia Nuclear (CDTN) pela recepção em sua planta piloto e sugestões para a confecção do equipamento aqui apresentado, a Mineração Curimbaba LTDA pela realização das análises químicas, a Fundação de Apoio da Universidade Federal de Alfenas pela gestão das compras dos materiais utilizados e as empresas Provitec e Oscartec Soluções em Equipamentos pelo fornecimento com descontos dos materiais utilizados.

\section{REFERÊNCIAS}

1 Persechini MAM, Jota FG, Oliveira MLM, Peres AEC. Instrumentação de uma coluna de flotação piloto para o desenvolvimento de técnicas de controle avançadas. Série Tecnologia Mineral. 2001 [acesso em 15 out. 2012]; 80: 1-40. Disponível em: http://www.cetem.gov.br/publicacao/series_stm/stm-80.pdf.

2 Oliveira MLM, Aquino JA. Aspectos relevantes das colunas de flotação. In: XXI Encontro Nacional de Tratamento de Minérios e Metalurgia Extrativa [evento na internet]. 2005 nov; Natal, Brasil [acesso em: 10 fev 2013]. Disponível em: http://www2.ifrn.edu.br/ojs/index.php/HOLOS/article/viewFile/87/91.

3 Leal Filho LS. Flotação. Belo Horizonte, 2007 (Apostila).

4 Aquino JA, Oliveira MLM, Fernandes MD. Flotação em coluna. In: Luz AB, Sampaio JA, Almeida SLM. Tratamento de minérios. 4. ed. Rio de Janeiro: CETEM/MCT; 2004. p. 459-494.

5 Araujo LR. Malhas de controle típicas no beneficiamento a úmido de minério de ferro[monografia de pós-graduação]. Ouro Preto: Escola de Minas da UFOP; 2010.

6 Takata LA. Flotação em coluna. In: Chaves AP. Teoria e prática do tratamento de minérios: a flotação no Brasil. 2.ed. São Paulo: Signus; 2009. p. 45-71.

7 Vieira AM. Efeito da granulometria na flotação de quartzo [tese de doutorado]. Belo Horizonte: Escola de Engenharia da UFMG; 2005.

\footnotetext{
* Contribuição técnica ao $44^{\circ}$ Seminário de Redução de Minério de Ferro e Matérias-primas, 15ํ Simpósio Brasileiro de Minério de Ferro e $2^{\circ}$ Simpósio Brasileiro de Aglomeração de Minério de Ferro, 15 a 18 de setembro de 2014, Belo Horizonte, MG, Brasil.
} 
8 Chaves AP, Leal Filho LS. Flotação. In: Luz AB, Sampaio JA, Almeida SLM. Tratamento de minérios. 4.ed. Rio de Janeiro: CETEM/MCT; 2004. p. 411-455.

9 Viana PRM. Prática industrial no beneficiamento de minério de ferro. In: Valadão GES, Araujo AC. Introdução ao tratamento de minérios. Belo Horizonte: Editora UFMG; 2007.p. 191-209.

10 Nunes DG, Couto HJB, França SCA. Aplicação da flotação em coluna na concentração de minério de ferro de baixo teor. In; XVIII Jornada de Iniciação Científica [evento na internet]. 2010 [acesso em 20 out 2012]. Disponível em:

http://www.cetem.gov.br/publicacao/serie_anais_XVIII_jic_2010/Daniel_Nunes.pdf.

11 Sampaio JA, Silva FANG. Determinação das densidades de sólidos e de polpa. In: Sampaio JA, França SCA, Braga PFA. Tratamento de minérios: práticas laboratoriais. Rio de Janeiro: CETEM/MCT; 2007.

12 Santos LMM, Siderurgia para cursos tecnológicos. Ouro Preto: ETFOP; 2007.

* Contribuição técnica ao $44^{\circ}$ Seminário de Redução de Minério de Ferro e Matérias-primas, 15ํ Simpósio Brasileiro de Minério de Ferro e $2^{\circ}$ Simpósio Brasileiro de Aglomeração de Minério de Ferro, 15 a 18 de setembro de 2014, Belo Horizonte, MG, Brasil. 